\title{
Digitalization of education: advantages and problems
}

\author{
Galina Marchenko ${ }^{1 *}$, Svetlana Murzina ${ }^{1}$, Sergey Timofeev ${ }^{1}$, and Kseniya Vodopyanova $^{2}$ \\ ${ }^{1}$ Don State Technical University, 344003, Rostov-on-Don, Russia \\ ${ }^{2}$ Donetsk National University, Donetsk, Ukraine
}

\begin{abstract}
The study is devoted to the problem of the increasing the influence of the distance learning format of education on students of different ages. The changes taking place in the modern world influense greatly on modern trends in the development of the education system. It is necessary to pay attention to particularities of person interaction with information and communication technologies, especially in the field of education. The aim of our investigation was to reveal the features of the influence of the distance learning format of education on schoolchildren middle and high school. To achieve this goal, sociological research methods such as questionnaires and interviews were applied. The results allowed us to conclude that younger students have more problems during distance learning such as: understanding new material, deficiency of attention, technical problems with computer, while teenagers and high school students handle with it more effectively. These data results will help modernize the educational process and make distance learning for schoolchildren easier and understandable,espessially for primary school students.
\end{abstract}

\section{Introduction}

Before the start of the pandemic of the new coronavirus infection, the development of world civilization was dominated by the processes of globalization, when natural, industrial and human resources freely moved across the borders of national states. This stimulated the rapid development of vehicles and communications, science and various technologies, which contributed to the dissemination of scientific, economic, political and other information at an unprecedented speed, which increased the role of information and communication technologies in the life of the country, society and every person [1]. The changes taking place in the modern world are factors of social causation of such trends in the development of the education system as fundamentalization, pragmatization, individualization, humanization, standardization, and computerization. Article 16 "Law of Education" the Russian Federation states that "E-learning is understood as the organization of educational activities using information contained in databases and used in the implementation of educational programs and information technologies, technical means, and information and telecommunication networks that ensure its processing, ensuring the transfer of the specified information through communication lines, the interaction of students and teaching staff. Distance learning technologies are understood as educational technologies implemented mainly with the use of information and telecommunication networks with indirect (at a distance) interaction

\footnotetext{
* Corresponding author: donpedagog2020@yandex.ru
} 
between students and teachers "Federal Law "On Education in the Russian Federation" dated December 29, $2012 \quad \mathrm{~N} \quad 273-\mathrm{FZ} \quad$ (last edition) http://www.consultant.ru/document/cons_doc_LAW_140174/.

In the last couple of decades, more and more studies dedicated to the study of the characteristics and influence of distance technologies on personal development and ensuring the quality of education have appeared $[2,3,4,5,6,7,8,9,10,11,12,13,14]$. "Back in 2018, at the 14-th major press conference the president of the Russian Federation expressed the idea that "we need to jump into a new technological order. Without this the country has no future. This is a fundamental question. ... It is necessary to concentrate the available resources, find them and concentrate on the most important areas of development" [15]. One of the most important resources that is necessary for the implementation of a technological breakthrough is a man and his knowledge, competence, experience, relationships. The training of a professional specialist, capable of highly skilled creative working, is one of the main directions that require the concentration of general efforts, the president Putin spoke about" [16].

Without questioning the positive role of digitalization in the development of the economy and ensuring national security, it is necessary to pay attention to the positive and negative aspects of human interaction with information and communication technologies, especially in the field of education [17]. On February 15, 2021, an Appeal from Moscow's parents to the highest authorities of the Russian Federation appeared, in which the parental community of the capital expressed its attitude to the program for reforming Russian education based on digitalization developed by economists, financiers, technocrats. One of the main claims of parents is that they, as legal representatives of children and equal participants in the educational process, do not take an active part in the public discussion of the directions of reforming the education system in our country. In addition, parents are concerned about the problems of spiritual and moral education of youth, which is possible only in the process of direct emotional communication between the teacher and the student, because the experience of emotional and value relationships is formed through adequate experiences, which the teacher's personality provides [18]. Moreover, parents are concerned with the problem of provision the electromagnetic safety of schoolchildren, preservation a healthy socio-cultural environment and the health of each child. But if parents have the opportunity to express their opinion through such form as an open appeal in social networks, then the opinion of schoolchildren remains out of attention of both the designers program of development of education and the general public.

\section{Materials and Methods}

The relevance of our study, dedicated to the problems of using distance learning tools, is due to the transformation of distance learning and information and communication technologies into a phenomenon of a global scale and an indicator of the level of a person's mastery of information culture. During the pandemic, distance learning has become a universal phenomenon, with which almost all schoolchildren and students in Russia have come into contact. Their practical experience in the implementation of distance learning deserves a primary generalization and systematization in order to determine the positive and negative aspects of introducing distance learning into the educational process.

Therefore, the purpose of our investigation is study the opinions of schoolchildren and forecasting trajectories of the further implementation and application of e-learning and distance technologies in the educational process.

To achieve this goal, the following tasks were solved:

- to determine what place the distance methods occupy in the process of acquiring knowledge; 
- to analyze the problems that schoolchildren have in the process of distance learning;

- to summarize the positive and negative in the process of organizing distance learning.

The hypothesis of the research is as follows, for the younger generation is more convenient use distance technologies, but we suggest that the quality of the acquired knowledge and the level of formed competencies will decrease and the harmful effect of ICT on children's health will increase.

The object of the research is distance learning as a pedagogical phenomenon that is becoming increasingly important.

Subject of research: features of the implementation of distance learning.

The investigation conducted in two schools in the Abinsk region of the Krasnodar area. As the respondents were students of the 4-th, 8-th and 11-th grades (43, 41 and 39 students respectively). As methods of scientific and pedagogical investigation, were used such methods as interviewing and questionnaire.

\section{Results}

During the interview, the students were asked only one question: "What problems and difficulties did you face when you had a distance learning?".

The responses received from the respondents were summarized and the results are presented below in diagrams (see Fig. 1-3).

\section{Problems of primary school pupils in distance learning (4 class)}

Failure to provide a supportive environment

Material insufficiency of ICT provision

Unformed voluntary attention

Lack of self-organizing skills

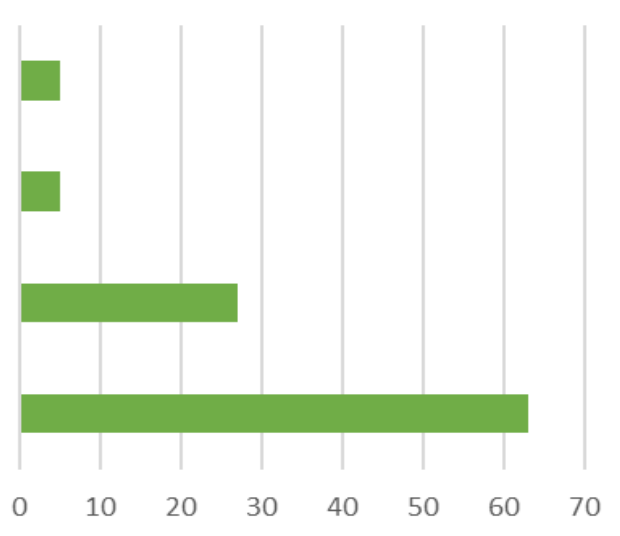

Fig. 1. Problems of primary school pupils in distance learning (4-th grade).

The results of the investigation showed that the problems faced by teenagers are of a somewhat different scheme (see Fig. 2). 


\section{Problems of teenagers in distance learning (8-th grade)}

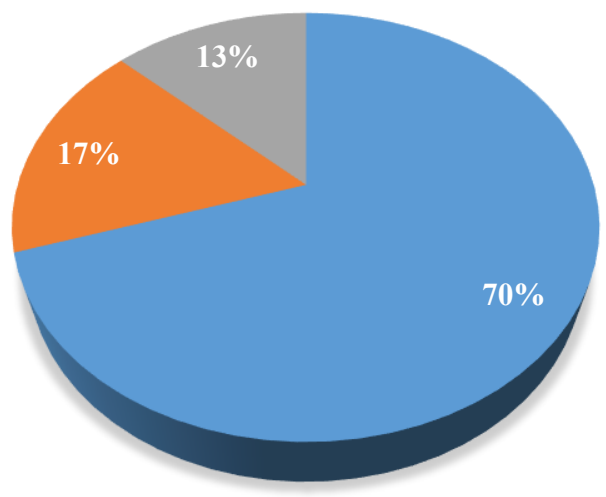

70 Lack of communication with peers

17 Biased assessment of learning outcomes

13 Lack of physical education lessons and health problems

Fig. 2. Problems of teenagers in distance learning (8-th grade).

High school students had problems preparing for the exams due to the lack of strict discipline, they complained about technical problems, which were the reason for the loss of class time, $13 \%$ noted blurred vision (see Fig. 3).

\section{High school students' problems in distance learning (11-th grade)}

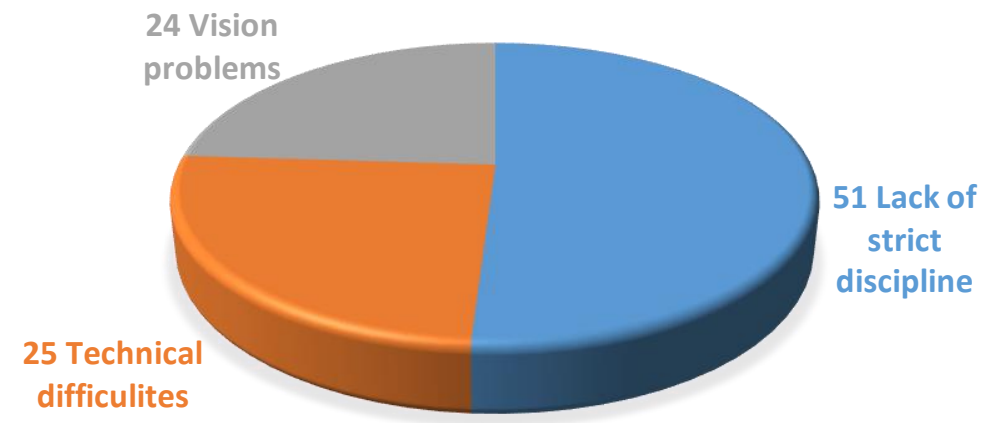

Fig. 3. High school students' problems in distance learning (11-th grade).

The next phase of the investigation was a questionnaire, for which a closed-type questionnaire was used, containing 4 questions, to which it was necessary to give either a positive answer "yes" or a negative one - "no". The questions were formulated in the following way : "How is it better for you to study: online or offline? Were there any difficulties in distance learning? Would you like to study further in a distance format? Do you always have the opportunity to study online?". The summarized results of the questionnaire presented in the diagram (see Fig. 4). 


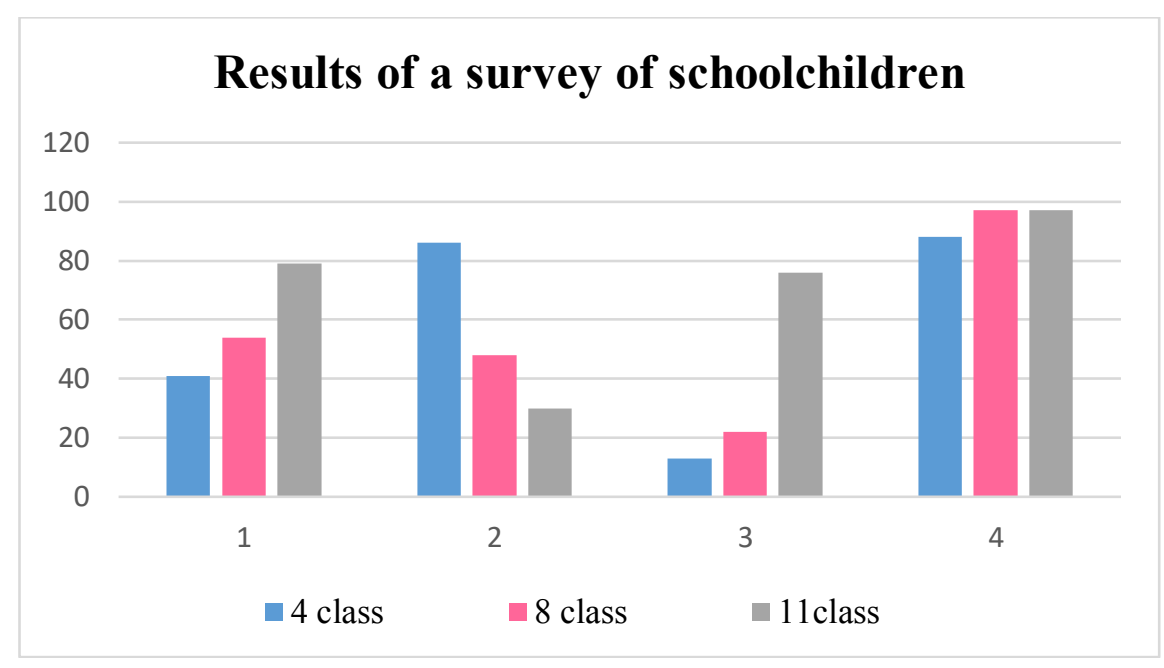

Fig. 4. Results of a survey of schoolchildren.

The aggregation of results of the interview gives reason to say that younger students are not quite ready for the transition to a distance-learning format due to their lack of skills in self-organization of educational activities out of direct contact with the teacher. Because of that they cannot sit at the monitors for a long time and are often distracted by subjects that are not related to the educational process, since their voluntary attention has not yet been fully formed, and it is difficult for a teacher to use means of activating attention in distance learning, younger students face a lack of direct communication with the teacher. Another difficulty was the lack of devices that could used in the educational process, and the inability to create and maintain a favorable educational environment at home, most often due to the presence of other children in the family (not enough computers, not enough free space, other children distracting and preventing from studying).

Given the fact that for a teenager, the leading activity is intimate and personal communication, its absence was the main problem for students of 8 -th grades, which they were unable cope with in the process of distance learning. Furthermore, teenagers noted the lack of objectivity in evaluation of the results of their educational work due to the possibility of writing off the answers to tasks using the Internet resources. An important problem for teenagers was the lack of physical education lessons, which led to limited movement, increased weight, back pain, and other health problems.

The results indicated that there are a number of significant deficiencies in distance learning that affect the level of knowledge and the physical condition of students (health problems, communication breakdown, difficulty in perceiving material for technical and other reasons, inconvenience or impossibility of obtaining knowledge in this format).

Based on the results of the questionnaire, the following conclusions can be made. Distance learning turned out to be more difficult for younger students, while teenagers and high school students cope with it more successfully. In the case of a transition to a distance format of education, primary school teachers need to review the ways of explaining new material for facilitation the solution of educational problems, to develop voluntary attention, and increase the level of discipline, which concerns almost all students. High school students are more organized, it is much easier for them to work in an information environment, focusing the attention on the necessary material. The vast majority of schoolchildren have all the opportunities for learning in a distance-learning format, but there is also a small percent of children who either have limited or no such opportunities for various reasons. 


\section{Discussion}

The educational systems of most countries experience significant transformations due to both the pedagogically controlled and the spontaneous, implicit influence of the latest technologies. Students and schoolchildren spend an increasing amount of study time in "communication" with personal computers (electronic textbooks, curriculum, electronic library resources, the Internet). It is almost impossible to train a competent specialist without taking into account the taking place changes. At the same time, the very understanding of literacy has changed, which is now viewed as a product of both pedagogical and information technologies, and the components of education are virtual, visual, mass media, multimedia types of literacy. The formation of an individual's information competence plays a positive role in increasing the level of his information culture, which should considered as an inalienable component of professional culture, which is convincingly proved by numerous modern studies.

Scientific-educational and information-communicational networks open wide opportunities for scientists, teachers, students in receiving direct access to various public databases, to educational, art and reference literature, to an information base of publications and joint participation in scientific projects, conferences, video bridges and etc. In circumstances of an ever-growing volume of information, the problems of finding scientifically reliable information on the Internet and creating electronic textbooks for the prompt transfer of updated educational material for use by all participants in the educational process actualized. In the conditions of the transition from the industrial and post-industrial to the information society, in the circumstances of informatisation of all spheres of social life, the school must prepare a future professional specialist who is able critically evaluate, select, analyze and synthesize, systematize the information that humanity accumulates in large amounts. Today, information and communication technologies are a significant part of world production, which leads to a global redistribution of both the labor market and the market of educational services, since the creation of global open educational and scientific systems makes it possible to develop a system for the accumulation and dissemination of scientific knowledge and makes open access to a variety of information resources to the general population. Modern technologies for creating, processing, transferring and storing information give the future professional very wide opportunities effectively solve production tasks. That's why, teachers are working on the problems of the effective inclusion of information-communicational technologies in the pedagogical process and preparing the future teacher for this. On this path, certain difficulties arise in view of the fact that information technologies are developing faster than pedagogical theory.

Access to higher education for all segments of the population, the dissemination of distance learning systems, the openness of education, the opportunity to receive higher education throughout life - these and other principles determine the need for substantial training of teachers, especially humanitarian subjects, for the use of information technologies in the pedagogical process.

Along with the advantages that distance learning with the use of information and communication technologies has, one cannot reject the negative aspects that schoolchildren note in our investigation.

\section{Conclusions}

The pedagogical (theoretical and methodological) opportunities of computer and other technical means of education and appropriate software systems determine the didactic potential and functions of information-communicational educational technologies. The continuous expansion of the sphere of application of information-communicational 
technologies necessitates the further computerization of the education system. Analysis and generalization of modern data from various sciences on the use of ICT in education and upbringing allow us to conclude that there are enough opportunities for the use of computer technologies with the aim of formation the spiritual and moral qualities of schoolchildren and students, for example, by means of art.

In addition, the introduction of a computer in the educational and upbringing process as a means of solving educational, instructional and developing tasks contributes to promotion interest and motivation for learning through new forms of work and a sense of belonging to the development of science and technique; intensification training and education through the use of bright, attractive and rapidly changing forms of presentation information.. As the advantages of ICT, their capabilities are considered: to provide the competitiveness of the student with the machine and with himself; individualize training; to increase the information base many times over and provide prompt access to it; get the necessary information in sufficient volume; to develop the intellectual, spiritual and moral potential of youth; to develop the ability to plan and rationally build labor operations, to accurately determine and formulate the goals of the activity; to form accuracy, precision, binding nature. As the advantages of ICT, their capabilities are considered: to provide the competitiveness of the student with the machine and with himself; individualize training; to increase the information base many times over and provide prompt access to it; get the necessary information in sufficient volume; to develop the intellectual, spiritual and moral potential of youth; to develop the ability to plan and rationally build labor operations, to accurately determine and formulate the goals of the activity; to form accuracy, precision, binding nature. Education, first of all, should focuses on the upbringing of a general culture of the individual, broad scientific erudition and a high humanistic feeling - the feeling of Love for a person.

The solution of this problem can contribute to the inclusion of ICT in the educational process. With the help of computer tools, you can create various forms of classroom and extracurricular classes activate the cognitive activity of schoolchildren and students, ensure the establishment of subject-subject relations, turn the schoolchild and student into an active figure and creator of their educational trajectory, form an educational environment that promotes the development of thinking, memory, imagination, attention, etc., as well as activity, initiative, creativity. Along with this, in the conditions of distance learning, we cannot ignore the limitation of real communication with peers and teachers, the possibility of a not entirely conscientious approach to the fulfilment of educational tasks, which distorts the final results of the learning process, the need to take into account the age and individual characteristics of schoolchildren and students, the negative influence on the health of students limitation their motor activity, insufficiency results of scientific researches in the field of electromagnetic safety.

The search and choice of ways to further improvement of the education system requires a wide discussion by all stakeholders of the advantages and disadvantages of distance learning and dictates the necessity taking into account the views of all participants of the educational process.

\section{References}

1. S.M. Murzina, A.D. Murzin, T.M. Rogova, European Proceedings of Social and Behavioural Sciences 35, 961-971 (2018)

2. S. Alirezabeigi, J. Masschelein, \& M. Decuypere, Media and Technology 45(2), 193207 doi.org/10.1080/17439884.2020.1727501 (2020a).

3. S. Alirezabeigi, J. Masschelein, M. Decuypere, Educational Philosophy and Theory. doi.org/10.1080/00131857.2020.1716335 (2020b). 
4. W. Benjamin, On the Concept of History, En H. Eiland \& M. W. Jenning (Eds.), The Belknap Press of the Harvard University Press 4, 389-400 (2003)

5. W. Benjamin, En P. Demetz (Eds.), Reflection. Essays, Aphorisms, Autobiographical Writings (Mariner Books, Naples, 2019).

6. M. Cacciari, Icone della legge (Adelphi, 1985)

7. Th. Cochrane, L. Antonczak, H. Keegan, \& V. Narayan, Research in Learning Technology 22, (2014) doi.org/10.3402/rlt.v22.24637

8. I. Dussel, The digital classroom: A Historical Consideration on the Redesigning of the Contexts of Learning, En I. Grosvenor, L. Rosén Rasmussen (Eds.), Making Education, Material School Design and Educational, 2018) doi.org/10.1007/978-3-319-97019-6_9

9. Governance. Educational Governance Research, Springer. 9, 173-196

10. H.-T. Hung, Interactive Learning Environments 25(8), 983-995 doi.org/10.1080/10494820.2016.1240090 (2017).

11. I. James, Paul Virilio. Routledge. doi.org/10.4324/9780203007631(2007).

12. J. Masschelein, \& M. Simons, In defence of the school (A public issue. Education, Culture \& Society Publishers) https://ppw.kuleuven.be/ecs/les/in-defence-of-theschool/jan-masschelein-maarten-simons-in-defence-of-the.pdf (2013).

13. Ministero dell'Istruzione, dell'Università e della Ricerca La buona scuola, Facciamo crescere il https://www.istruzione.it/allegati/2014/LA_BUONA_SCUOLA_Rapporto_3_ settembre_2014.pdf (2014).

14. J. Vlieghe, Philosophy and Technology 27(4), 519-553 doi.org/10.1007/s13347-0130131-x (2014).

15. V. Putin, We need a breakthrough, we need to jump into a new technological order, without this the country has no future. https://www.1tv.ru/news/2018-12 -20 / 357610vladimir_putin_nam_nuzhen_proryv_nuzhno_prygnut_v_novyy_tehnologiches kiy_uklad_bez_etogo_u_strany_net_buduschego] (07.12.2020).

16. G. Marchenko, S. Timofeev, K. Vodopianova, Extracurricular activities of students $-a$ means of forming professional motivation, (ITSE-2020) E3S Web of Conferences 210, 18028 (2020) doi.org/10.1051/e3sconf/202021018028

17. T.Y. Anopchenko, A.D. Murzin, S.M. Murzina, European Proceedings of Social and Behavioural Sciences, 59, 777-784 (2019)

18. S. Murzina, S. Timofeev, Cross-border model of young personnel professional identity formation, in Rostov region agro-industrial complex, (ITSE-2020) E3S Web of Conferences 210, 22018 (2020) doi: https://doi.org/10.1051/e3sconf/202021022018] 